\title{
A Rare Case of Tibiotalar Dislocation in a Rabbit and Its Management
}

\author{
A. Velavan, N. Krishnaveni", H. Pushkinraj and Heera Banu \\ Department of Veterinary Surgery and Radiology, Madras Veterinary College, Tamilnadu \\ Veterinary and Animal Sciences University, Chennai-600 007, India \\ *Corresponding author
}

\section{A B S T R A C T}

\begin{tabular}{|l|}
\hline Ke y w o r d s \\
Tibiotalar Dislocation, \\
Rabbit, Radiology
\end{tabular}

\section{Introduction}

Postero-lateral dislocation of the tibiotalar joint without fracture is an unusual injury (Soyer et al., 1994). Tibiotalar dislocations are classified into five types based on the direction of the dislocation: anterior, posterior, medial, lateral or, superior combined. Tibiotalar dislocation without concomitant fracture occurs when the ankle sustains a combination of inversion and axial loading forces during maximal plantar flexion of the foot (Uyar et al., 2004).

\section{Case history and observation}

A 1.5 years old male rabbit was presented with the history of non-weight bearing lameness on left hindlimb. Clinical examination revealed pain, crepitus and a punctured wound on the tibiotalar joint. Orthogonal view of plain radiography of left hindlimb revealed postero-lateral tibiotalar dislocation (Figure 1).

\section{Treatment and Discussion}

Temporary immobilisation was done with soft cotton bandage. Mask induction was done with isoflurane $4 \%$ and $100 \%$ oxygen. General anesthesia was maintained with $2 \%$ isoflurane. Left hindlimb was aseptically prepared for surgery. Traction was applied. Normograde intramedullary pinning was done by using 1.2 mm Kirshner wire (Figure 2). Intraoperative C- arm radiography confirmed the position and placement of intramedullary pin. Soft cotton bandage was applied postoperatively. 


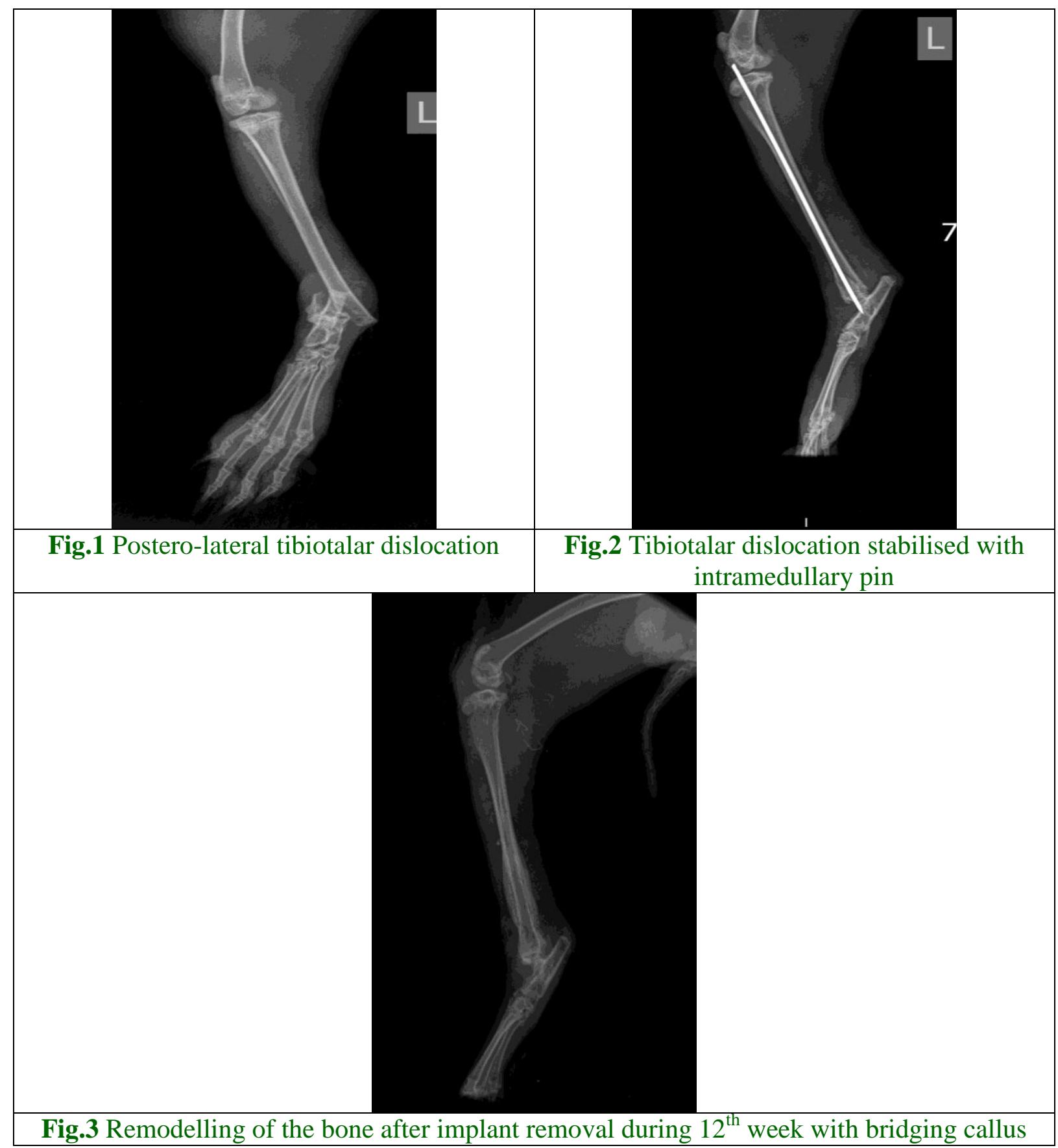

Bandaging and wound cleaning was done on alternative days for a week. Restricted movement and confinement was advised for next three weeks follow up. Postoperative radiograph revealed periosteal and bridging callus formation on $4^{\text {th }}$ week (Figure 3 ). Full weight bearing and normal range of motion was achieved on $6^{\text {th }}$ week postoperatively. Implant removal was done $12^{\text {th }}$ week postoperatively. Animal had an uneventful recovery.

Tibiotalar dislocation without fracture is rare and usually due to a high traumatic energy mechanism. Among the four types of dislocation, postero-lateral is common and associated with cutaneous injuries. Treatment involves closed surgical reduction followed 
by immobilisation. Prognosis is good and requires long term monitoring to combat the appearance of subtalar arthrosis (Azarkane et al., 2014).

In the present case, tibiotalar dislocation was successfully managed with closed reduction using intramedullary pinning.

\section{References}

Azarkane, M., H Boussakri, A. Alayyoubi, M. Bachiri, A. Elibrahimi and A. Elmiri. (2014). Closed medial total subtalar joint dislocation without ankle fracture: a case report. J Med Case Rep 8(313): 1-4.

Soyer, D. A., B. J. Nestor and S. J. Friedman. (1994). Closed posteromedial dislocation of the tibiotalar joint without fracture or diastasis: a case report. Foot Ankle Int 15: 622-624.

Uyar, M., A. Tan, M. Isler and E. Centinus. (2004). Closed posteromedial dislocation of the tibiotalr joint without fracture in a basketball player. $\mathrm{Br} \mathrm{J}$ Sports Med 38: 342-343.

\section{How to cite this article:}

Velavan, A., N. Krishnaveni, H. Pushkinraj and Heera Banu. 2018. A Rare Case of Tibiotalar Dislocation in a Rabbit and Its Management. Int.J.Curr.Microbiol.App.Sci. 7(08): 1628-1630. doi: https://doi.org/10.20546/ijcmas.2018.708.186 